(1). ER was successful in a mean of 1.46 procedures per patient (range 1-3). Complication rate was 5.2\% (4 bleeds, 1 microperforation, 2 strictures). Additional RFA was used in 11 cases. 12 (20\%) of patients developed recurrence of HGIN/IMC during follow-up requiring further endoscopic therapy. $2(3.4 \%)$ patients developed more advanced Barrett's neoplasia during follow-up. The calculated cost per patient of an ER-dominant approach is $£ 4125$ compared to $£ 8868$ per patient for an RFA dominant approach.

Conclusion ER acted as an accurate and safe staging procedure in up to $23 \%$ of cases found to have advanced histology. ER is an effective and safe treatment for HGIN/IMC within Barrett's oesophagus without the need for routine RFA and can be performed successfully in a UK centre. However the recurrence of HGIN/IMC is not uncommon and therefore close follow-up is required to identify and treat it at an early stage. An ER-dominant approach may offer significant cost-savings compared to an RFA-dominant approach without compromising overall outcomes.

Disclosure of Interest None Declared

\section{PTU-165 THE BETTER DEFINITION OF NODAL STAGING IN THE 7TH EDITION OF TNM MANUAL DOES NOT PREDICT SURVIVAL OR TRANSLATES INTO BETTER PROGNOSTICATING ABILITY IN OESOPHAGO-GASTRIC JUNCTIONAL ADENOCARCINOMA}

doi:10.1136/gutjnl-2013-304907.255

1."R Y Kannan, 'M Davies, 'C Jenkins, 'A Rasheed. 'Institute of Minimal Access Surgery, Royal Gwent Hospital, Newport, UK

Introduction The 7th TNM staging defines a minimum number of nodes, recommends an optimal number for each $\mathrm{T}$ stage, emphasises the prognostic importance of number of regional nodes involved and upstages based on the number of metastatic lymph nodes. We intend on studying the impact of application of 7 th TNM rules on nodal staging $(\mathrm{N})$ of resected and pathologically reported oesophago-gastric junctional (OGJ) adenocarcinomas during the last 10 years stratifying them according to the 7 th edition TNM staging and to compare against the original staging and assess possible impact of nodal neo-staging on survival.

Methods A retrospective database was used to capture the clinicopathological data of all consecutive curative resections of OGJ adenocarcinomas over the last 10 years in two UK Upper GI Units. Any report with less than 12 lymph nodes was considered inadequate and denoted as $(\mathrm{Nx})$. All cases were re-reported and re-staged according to the 7th TNM staging rules. We compared the impact of the 7th TNM staging rules on neo-staging. Overall survival was analysed using the 6th and 7th TNM staging respectively. Overall survival was sub-stratified into 2 years, 5 years and 10 years post curative resection.

Results Fifty seven (57) pathology reports confirming OGJ adenocarcinomas were reviewed. Adequate lymphadenectomy (minimum of 12 nodes) was noted in 33 patients. Overall stage migration was noted in $36(63 \%)$ reports with the 7 th TNM staging. Of those who had adequate lymphadenectomy (33), 20 reports(60.6\%) had stage migration. Survival was calculated from the time of initial surgery. Two year survival was assessed in the whole group $(n=57)$. Five year survival for patients operated between 2000 to $2007(n=34)$ and 10 year survival for those operated on between 2000 to $2002(n=10)$. For stage $3 \mathrm{~b}$ and stage $3 \mathrm{c}$ (7th TNM) there was a $12.5 \%, 8.9 \%$ and $8.9 \%$ higher survival rate respectively (for 2.5 and 10 years), compared to the original 6th TNM staging for stage 3 . Correspondingly for stage $1 \mathrm{~b}$, the survival rate was $5.3 \%, 3.6 \%$ and $3.6 \%$ respectively. Conclusion The 7 th edition of TNM staging provides a detailed documentation of the lymphatic staging. This better defined lymphatic staging does not seem to predict survival or have a superior prognosticating ability.

Disclosure of Interest None Declared

\section{PTU-166 DIAGNOSIS OF GASTRO-0ESOPHAGEAL REFLUX DISEASE (GORD) BY HISTOLOGY OF MUCOSAL BIOPSIES FROM DISTAL OESOPHAGUS: AGREEMENT WITH PROLONGED PH MONITORING}

doi:10.1136/gutjnl-2013-304907.256

1. ${ }^{*} \mathrm{R}$ Sweis, ${ }^{2} \mathrm{~F}$ Chang, ${ }^{3} \mathrm{M}$ Fox, ${ }^{4} \mathrm{~A}$ Anggiansah, ${ }^{1} \mathrm{~A}$ Lee, ${ }^{1} \mathrm{~A}$ Valdes, ${ }^{5} \mathrm{~T}$ Wong. 'Oesophageal lab; ' ${ }^{H i s t o p a t h o l o g y ~ D e p a r t m e n t, ~ S t ~ T h o m a s ' ~ H o s p i t a l, ~ L o n d o n ; ~}{ }^{3}$ NIHR Biomedical Research Unit and Digestive Diseases Centre, Nottingham University Hospitals, Nottingham; ${ }^{4}$ Oesophagael lab; ${ }^{5}$ Gastroenterology Department, St Thomas' Hospital, London, UK

Introduction Prolonged wireless $\mathrm{pH}$-monitoring (Bravo) increases diagnostic yield compared to $24 \mathrm{hr} \mathrm{pH}$-studies. Studies have shown a weak association between oesophageal acid exposure from $24 \mathrm{hr}$ $\mathrm{pH}$-studies and mucosal disease on distal oesophageal histology. This study assessed the association between Bravo, endoscopic findings and distal oesophageal histology.

Methods From July 2009 to August 2010, 63 consecutive patients with typical reflux symptoms had endoscopy with biopsies taken from $3 \& 9$ o'clock position at and $2 \mathrm{~cm}$ proximal to the Z-line prior to $\mathrm{pH}$ capsule fixation $6 \mathrm{~cm}$ proximal to the Z-line for prolonged (up to $96 \mathrm{hr}$ ) Bravo. All biopsies were assessed by the 6-parameter Zentilin histology score (Zentilin et al Gastroenterol 2005). GORDdiagnosis was based on "Average" acid exposure (Total Reflux; TR $>5.3 \%$ time $\mathrm{pH}<4$ ) over the time period measured and/or symptom-association (symptom index; SI $>50 \%$ )

Results Adequate biopsy samples were available from 57/63 patients (mean age 44 (range 17-78); 27M). 37/57(65\%) patients had GORD based on either TR $(\mathrm{n}=30)$ or SI $(\mathrm{n}=32) .20 / 57(35 \%)$ were both TR \& SI negative (Functional Heartburn; FH). 18 FH patients had no mucosal changes, 2 had grade A oesophagitis. There was no difference in individual histology parameters between GORD vs. FH ( $p>0.05)$ apart from increased 'intra-epithelial neutrophils' (IEN) at the Z-line ( $9 / 37$ vs. $1 / 20$ positive; $p=0.031)$ and $2 \mathrm{~cm}$ proximally ( $6 / 37$ vs. $0 / 20$ positive; $p=0.012$ ). The combined Zentilin histology score was also higher in GORD at the Z-line $(p=0.079)$ and $2 \mathrm{~cm}$ proximally $(p=0.05)$.

Using GORD diagnosis from $96 \mathrm{hr}$ Bravo as reference, ROC analysis revealed that, although sensitivity remained poor, specificity of GORD diagnosis based on histology improved with IEN and total histology score. With increased IEN, sensitivity was 30\% at the Z-line and 20\% $2 \mathrm{~cm}$ above while specificity was $92.6 \%$ at the Z-line and $100 \% 2 \mathrm{~cm}$ proximally. For the optimal Zentilin histology score of $\geq 7$, sensitivity was $40.5 \%$ at the Z-line and $18.9 \% 2 \mathrm{~cm}$ above while specificity was $95 \%$ at the Z-line and $100 \% 2 \mathrm{~cm}$ proximally.

Histology corroborated GORD diagnosis (based on positive TR) in $11 / 30$ and $20 / 30$ patients at the Z-line and in $6 / 30$ and $11 / 30$ patients $2 \mathrm{~cm}$ proximally.

Conclusion Histology lacks sensitivity as a stand-alone diagnostic test; however high IEN or total histology scores have high specificity for GORD diagnosis based on $\mathrm{pH}$-study results. Thus, routine biopsy of the distal oesophagus may be sufficient to diagnose GORD and obviate the need for ambulatory $\mathrm{pH}$-studies in this subgroup of patients.

Disclosure of Interest None Declared.

\section{PTU-167 DIFFERENCES IN BARRETT'S OESOPHAGUS IN AN ETHNICALLY DIVERSE SOUTH LONDON POPULATION}

doi:10.1136/gutjnl-2013-304907.257

1,*'R Hewett, ' 'J-Y Kang, 'A Poullis. 'Gastroenterology, St George's, University of London, London, UK

Introduction Barrett's oesophagus $(\mathrm{BO})$ is a metaplastic change of the lining of the oesophagus; the normal squamous epithelium is replaced by specialised columnar epithelium. BO is a risk factor for 